\title{
Properties of biobased epoxy resins from epoxidized linseed oil (ELO) crosslinked with a mixture of cyclic anhydride and maleinized linseed oil
}

\author{
M. D. Samper*, J. M. Ferri, A. Carbonell-Verdu, R. Balart, O. Fenollar \\ Instituto de Tecnología de Materiales (ITM), Universitat Politècnica de València (UPV), Plaza Ferrándiz y Carbonell 1, \\ 03801 Alcoy (Alicante), Spain
}

Received 26 September 2018; accepted in revised form 4 December 2018

\begin{abstract}
This works aims at the development thermosetting resins derived from epoxidized linseed oil (ELO) of high biobased content, by using a mixture of crosslinking agents, i.e. methyl nadic anhydride (MNA) and maleinized linseed oil (MLO). By using only MNA as crosslinking agent, the obtained resins are characterized by high stiffness and, consequently, high fragility. When MLO content increasing in the crosslinking mixture, up to $25 \mathrm{wt} \%$, a decrease in mechanical resistant and thermomechanical is detected, thus indicating that MLO can provide flexibility to ELO-based thermosetting resins which is an interesting issue to obtain tailored properties by selecting the appropriate mixture composition. In general, the thermosetting resin crosslinked with $10 \mathrm{wt} \%$ MLO and $40 \mathrm{wt} \%$ MNA gives balanced properties together with noticeable biobased content, thus broadening the potential of these materials for uses in green composites and coatings.
\end{abstract}

Keywords: termosetting resins, epoxidized linseed oil, crosslinking, cyclic anhydrides, modified vegetable oils

\section{Introduction}

During the last years, a noticeable increase in the sensitiveness to environmental issues has been observed and polymeric materials of vegetable origin have attracted important attention in the last decades since they represent a feasible alternative to petroleum-derived materials. The development of biobased/ biodegradable thermoplastic polymers has been widely studied in the last few decades and today and it is interesting to remark the increasing use of biopolyesters such as poly(lactic acid) - (PLA), poly( $\varepsilon$-caprolactone) - (PCL), poly(butylene succinate) - (PBS), poly(butylene adipate-co-terephthalate) - (PBAT), poly(butylene succinate- $c o$-adipate) - (PBSA), and so on, among others [1-7]. With regard to biobased thermosetting resins, industry faces a great challenge which is total or partial substitution of petroleumderived resins with new environmentally friendly developments. It is possible to make polyurethane resins with vegetable oils like epoxidized rapeseed oil [8], castor oil, linseed oil [9], soybean oil [10] or cotton seed oil [11]. However, among all thermosetting resins, epoxy resins owe a privileged position as technical resins, low volatile generation, etc. Nevertheless, most industrial epoxy resins are derived from bisphenol-A which could be related to negative effects on health as well as high environmental impact [12]. For these reasons, bisphenol-A free epoxy resins are continuously being searched. It is possible to obtain biobased epoxy resins with different approaches. In the last years, many investigations have been developed and characterized in the field of epoxy resins from vegetable oils such as epoxidized linseed oil (ELO) [13-17], modified soybean oil [15, 16, 18-24] and other less known oils such as those derived from microalgal oil [25], jatropha oil [26], 
karanja oil [27], tung oil [28], cottonseed oil [29] or hemp oil [30]. However, there are other natural sources that make possibly the synthesis of epoxy resins like Vainillin [31-33], ferulic acid obtained from wheat bran and beetroot pulp [34] or abietic acid obtained from rosin [35].

Although some epoxy resins can crosslink by a homopolymerization process, the most common situation includes the use of a hardener or crosslink agent which in turn, will play a key role on final properties of the crosslinked material. It is quite usual the use of amines and anhydrides from petroleum as crosslinkers for epoxy resins [36]. Continuous exposure to these products can produce damages on health, induce rhinitis, conjunctivitis and asthma [21]. For this reason, it is important to search for new environmentally friendly hardeners to totally or partially substitute petroleum-derived hardeners. With this aim, Chen et al. [18] developed epoxy resins with a high bio-based content using epoxidized soybean oil (ESBO) crosslinked with modified maleopimaric acid from. Yang et al. [37] developed two different crosslinking agents from myrcene (a monoterpene) and castor oil to crosslink a commercial epoxy resin (E-51) with high elongation at break. Roudsari et al. [21] used sebacid acid as crosslinker in epoxy resins composed of a mixture of a diglycidyl ether of bisphenol-A epoxy (DGEBPA) resin and ESBO. Kadam et al. [27] used citric acid and tartaric acid as crosslinker to obtain epoxy resin using epoxidized karanja oil and they compared these resins with petroleum epoxy resins and their thermal stability were similar. Regarding the use of amines, Darroman et al. [38] synthesized an amine adduct from cardanol and cysteamine that was used as crosslinker in epoxidized cardanol resins. The presence of aromatic rings allowed obtaining epoxy-amine formulations with interesting uses in the coating industry. And Stemmelen et al. [39] modified grapeseed oil using cysteamine chloride by thiol-ene coupling to obtain polyamine grapeseed oil that they used as crosslinked agent to obtain epoxy resin using ELO and it presented a $T_{\mathrm{g}}$ around $-38^{\circ} \mathrm{C}$.

One of the most attracting uses of epoxy resins from vegetable oils is their use as matrices in composite materials with technical fibers such as basalt or slate fibers, and natural fibers to substitute, mainly, glass fiber reinforced composite parts with new environmentally friendly solutions. It has been reported the use of different natural fibers such as flax [40, 41], sisal [42], hemp [43], among others as reinforcing fibers in composites with biobased epoxy matrices, due to their low weight and for being renewable. One of the main drawbacks of these green composites is their low tensile and flexural strength compared to conventional epoxy/glass fiber composites (with a tensile strength of about $250 \mathrm{MPa}$ ) [44]. In contrast, the use of mineral fibers is still an excellent solution since mechanical properties are remarkably improved. Samperand and coworkers $[45,46]$ manufactured green composites with slate and basalt fibers subjected to a previous surface treatment with different silanes. The epoxy matrix was epoxidized linseed oil (ELO) or epoxidized soybean oil (ESBO) and composite materials with a tensile strength of $350 \mathrm{MPa}$ were obtained.

This research work aims at the development of high renewable content epoxy resins by using epoxidized linseed oil (ELO) and a mixture of two crosslinking agents: one conventional petroleum-derived cyclic anhydride, i.e. methyl nadic anhydride (MNA) and a vegetable oil derived anhydride, i.e. maleinized linseed oil (MLO). The optimum curing and post-curing conditions have been optimized by using differential scanning calorimetry (DSC) and oscillatory rheometry (OR) as well as a full characterization by flexural tests, mechanical-dynamical thermal analysis (DMTA), thermomechanical tests to obtain Vicat softening temperature (VST) and heat deflection temperature (HDT).

\section{Materials and methods}

\subsection{Materials}

A commercial epoxidized linseed oil (ELO) with an epoxy equivalent weight $(\mathrm{EEW})$ of $178 \mathrm{~g} \cdot$ equiv $^{-1}$ supplied by Traquisa S.A. (Madrid, Spain), was used as base epoxy resin due to their high number of oxirane groups in the triglyceride molecule that allows to obtain a resin with higher properties than if ECSO, epoxidized cottonseed oil, or other epoxidized vegetable oil (EVO) is used, since they have fewer oxirane groups per molecule. Two different crosslinking agents were mixed to cure the ELO resin. These two crosslinkers were a petroleum-derived cyclic anhydride methyl nadic anhydride (MNA) supplied by Sigma Aldrich Química S.A. (Madrid, Spain) and a maleinized linseed oil (MLO), MLO Veomer LIN, supplied by Vandeputte (Mouscron, Belgium) with a viscosity of $1000 \mathrm{cP}$ at $20^{\circ} \mathrm{C}$ and an acid value between 105 and $130 \mathrm{mg} \mathrm{KOH} \cdot \mathrm{g}^{-1}$. MNA was used as 
crosslinking to develop epoxy resins in previous laminates materials studies $[45,46]$ and it has been used in this work with the objective to reduce their content in the epoxy resins developed. As initiator, glycerol (99\%) was used and the selected accelerator was 1-methyl imidazol (1MI), both supplied by Sigma Aldrich Química S.A. Figure 1 shows the chemical structure of all the above mentioned chemical compounds.

The base formulation to cure the ELO resin was composed of ELO/MNA with an EEW/AEW (Epoxy Equivalent Weigth/Anhydride Equivalent Weigth) ratio of 1.0. Then, up to $25 \mathrm{wt} \%$ MNA was substituted by MLO as indicated in Table 1. Additional $1 \mathrm{wt} \%$ glycerol and $2 \mathrm{wt} \% 1 \mathrm{MI}$ (with regard to the mixture of ELO and mixture hardener) were used. All the components were mechanically mixed until homogenization and subsequently poured into a poly(tetrafluorethylene) - (PTFE) mold to obtain samples sizing $80 \times 10 \times 4 \mathrm{~mm}^{3}$. The liquid mixtures were subjected to a curing cycle of $2 \mathrm{~h}$ at $110^{\circ} \mathrm{C}$ followed by a post-cure stage at $160^{\circ} \mathrm{C}$ for 2 additional $\mathrm{h}$. The curing conditions used in this work for ELO-based thermosetting resins will hardly be used at the industrial level due to high temperature is needed and long curing times as well. Nevertheless, by using these

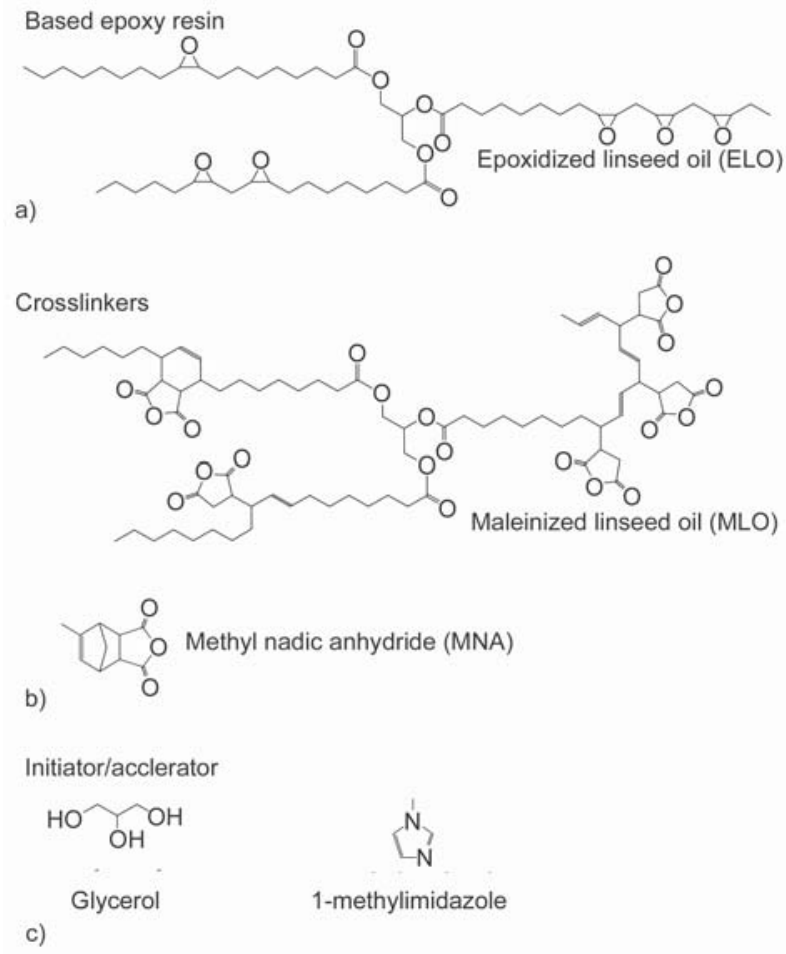

Figure 1. Schematic plot of the chemical structures of a) biobased epoxy resin from epoxidized linseed oil (ELO), b) anhydride-type crosslinkers and c) initiator and accelerator.
Table 1. Formulations of thermosetting resins based on epoxidized linseed oil (ELO) crosslinked with a mixture of anhydrides, i.e. methyl nadic anhydride (MNA) and maleinized linseed oil (MLO).

\begin{tabular}{|c|c|c|c|}
\hline Sample code & $\begin{array}{c}\text { ELO } \\
{[\mathbf{w t} \%]}\end{array}$ & $\begin{array}{c}\text { MNA } \\
{[\mathbf{w t} \%]}\end{array}$ & $\begin{array}{c}\text { MLO } \\
{[\mathbf{w t} \%]}\end{array}$ \\
\hline $50 / 0$ & 50 & 50 & 0 \\
\hline $45 / 5$ & 50 & 45 & 5 \\
\hline $40 / 10$ & 50 & 40 & 10 \\
\hline $35 / 15$ & 50 & 35 & 15 \\
\hline $30 / 20$ & 50 & 30 & 20 \\
\hline $25 / 25$ & 50 & 25 & 25 \\
\hline
\end{tabular}

conditions it is possible to reach the best mechanical performance on cured materials. In general, the use of amine-based hardeners allows curing at lower temperatures but anhydrides require higher curing temperatures to trig the reaction. Industrially, anhydrides are the selection for high performance cured epoxies [36].

\subsection{Study of the curing process of ELO-based thermosetting resins}

The curing study was followed by differential scanning calorimetry (DSC) and parallel plate oscillatory rheometry (OR). The DSC analysis was conducted in a DSC calorimeter 821 from Mettler-Toledo (Schwerzenbach, Switzerland). All the liquid mixtures were subjected to a dynamic curing cycle from 30 up to $300^{\circ} \mathrm{C}$ at a heating rate of $5^{\circ} \mathrm{C} \cdot \mathrm{min}^{-1}$. Isothermal curing process at $110^{\circ} \mathrm{C}$ was followed by oscillatory rheometry in a AR-G2 rheometer from TA instruments (New Castle, USA). The procedure was configured with parallel plates with a diameter of $25 \mathrm{~mm}$. The maximum deformation was set to $0.1 \%$ $(\gamma)$ and the selected frequency was $1 \mathrm{~Hz}$. The gel time was obtained as the crossover point between the storage modulus $\left(G^{\prime}\right)$ and the loss modulus $\left(G^{\prime \prime}\right)$.

\subsection{Study of post-curing process}

The optimum post-curing conditions were studied by dynamic-mechanical thermal analysis (DMTA) using as reference the crosslinked resin OMLO (50 wt $\% \mathrm{ELO} / 50 \mathrm{wt} \% \mathrm{MNA}$ ) after a post-curing process of $2 \mathrm{~h}$ at $110^{\circ} \mathrm{C}$. Different post-curing temperatures in the $140-180^{\circ} \mathrm{C}$ and different times (1$2 \mathrm{~h}$ ) were used. The dynamic-mechanical properties (storage modulus, $G^{\prime}$ and damping factor, $\tan \delta$ ) were obtained in an oscillatory rheometer AR G2 from TA Instruments (New Castle, USA) equipped with an accessory for solid samples working in torsion/shear 
conditions. Samples sizing $40 \times 10 \times 4 \mathrm{~mm}^{3}$ were subjected to a temperature sweep from 30 up to $200^{\circ} \mathrm{C}$ at a constant heating rate of $2{ }^{\circ} \mathrm{C} \cdot \mathrm{min}^{-1}$. The selected frequency was $1 \mathrm{~Hz}$ and the maximum allowed deformation $(\gamma)$ was $0.1 \%$.

\subsection{Mechanical and morphological characterization}

Standard flexural tests were carried out in a universal test machine ELIB 30 from S.A.E. Ibertest (Madrid, Spain). All tests were run at room temperature and using a crosshead speed of $5 \mathrm{~mm} \cdot \mathrm{min}^{-1}$ using a load cell of $5 \mathrm{kN}$. At least five different samples were tested and averaged following the guidelines of ISO 178 . The Shore D hardness was obtained using a Shore D 673-D durometer from Instrumentos J. Bot S.A. (Barcelona, Spain) using samples with a thickness of $4 \mathrm{~mm}$. Five different measurements were carried out and average values were calculated.

To observe the fracture surface, samples were cryofractured using liquid nitrogen and then it was observed by field emission scanning electron microscopy (FESEM) in a ZEISS ULTRA microscope from Oxford Instruments (Oxfordshire, United Kingdom) using an acceleration voltage of $2 \mathrm{kV}$. Prior to sample observation by FESEM, an ultrathin platinum layer was sputtered using a high vacuum sputtering coater EM MED020 from Leica Microsystems (Buffalo Grove, Illinois, USA).

\subsection{Thermo-mechanical characterization}

A thermomechanical analysis was carried out on cured and post-cured materials in a Q400 thermomechanical analyser from TA Instruments (New Castle, Delaware, USA). Squared samples $\left(10 \times 10 \mathrm{~mm}^{2}\right)$ and an average thickness of $4 \mathrm{~mm}$ were subjected to a TMA analysis in expansion from 20 up to $15^{\circ} \mathrm{C}$ at a heating rate of $2^{\circ} \mathrm{C} \cdot \mathrm{min}^{-1}$ with a normal force of $20 \mathrm{mN}$. All the tests were run under nitrogen atmosphere with a flowrate of $250 \mathrm{ml} \cdot \mathrm{min}^{-1}$. The heat deflection temperature (HDT) was measured following ISO 75-1. The selected method was ' $A$ ' which recommends a load of 1.8 MPa and a heating rate of $120^{\circ} \mathrm{C} \cdot \mathrm{h}^{-1}$. Regarding the Vicat softening temperature (VST), ISO 306 was used as the standard. VST values were obtained using the 'B' method which recommends a load of $50 \mathrm{~N}$ and a heating rate of $50^{\circ} \mathrm{C} \cdot \mathrm{h}^{-1}$. Both VST and HDT tests were carried out in a standard VICAT/HDT DEFLEX 684-As from Metrotec S.A. (San Sebastián, Spain).

\section{Results and discussion \\ 3.1. Characterization of the curing and post-curing process of ELO-based thermosetting resins crosslinked with MNA/MLO mixtures}

The curing cycle in a thermosetting resin is a key issue to obtain good properties. To evaluate this, dynamic differential scanning calorimetry (DSC) was used. Figure 2 shows a plot comparison of the exothermic peak attributable to the crosslinking process. As it can be seen, the crosslinking process starts at about $98-107^{\circ} \mathrm{C}$ and ends between $225-235^{\circ} \mathrm{C}$, depending on the composition of the mixture hardener. It is worthy to note that the peak temperature, which represents the maximum reaction rate, shows a decreasing tendency as the MLO increases. In fact, it changes from $176.9^{\circ} \mathrm{C}$ for ELO system crosslinked with the MNA/MLO (50/0) mixture down to values of $168.4^{\circ} \mathrm{C}$ for the crosslinked system with a MNA/ MLO (25/25) mixture. In addition, the enthalpy also shows the same tendency. The maximum reaction enthalpy is obtained with the MNA/MLO (50/0) mixture with a value of $126.0 \pm 5.4 \mathrm{~J} \cdot \mathrm{g}^{-1}$. As the MLO content increases, the peak enthalpy decreases thus indicating that MLO leads to less exothermicity. Thus, the ELO resin cured with the MNA/MLO (45/5) mixture shows a slight decrease in the enthalpy value $\left(124.7 \pm 2.4 \mathrm{~J} \cdot \mathrm{g}^{-1}\right)$ while the crosslinked system the MNA/MLO (25/25) mixture reaches lowest values of $89.7 \pm 5.1 \mathrm{~J} \cdot \mathrm{g}^{-1}$. This less exothermic values are directly related to the MLO chemical structure with a molecular weight over $900 \mathrm{~g} \cdot \mathrm{mol}^{-1}$. These macromolecules increase the weight but the number of epoxide groups per gram are lower than in MNA. For this reason, as the MLO content increases, the peak enthalpy also decreases.

The gel time was measured through oscillatory rheometry at isothermal conditions $\left(110^{\circ} \mathrm{C}\right)$. This particular isothermal temperature was selected considering that the onset of the crosslinking process is located between $80-100^{\circ} \mathrm{C}$ as observed previously by DSC analysis. At the initial stage, the liquid mixture shows a phase angle of $90^{\circ}$, typical of liquids which indicates that the deformation phasor is delayed with regard to the applied stress phasor by $90^{\circ}$. When the resin is fully cured, it behaves as a typical elastic solid in which, the deformation phasor is in phase with the applied stress phasor. For this reason, it is possible to follow the crosslinking process by following the evolution of the phase angle $(\delta)$ with 


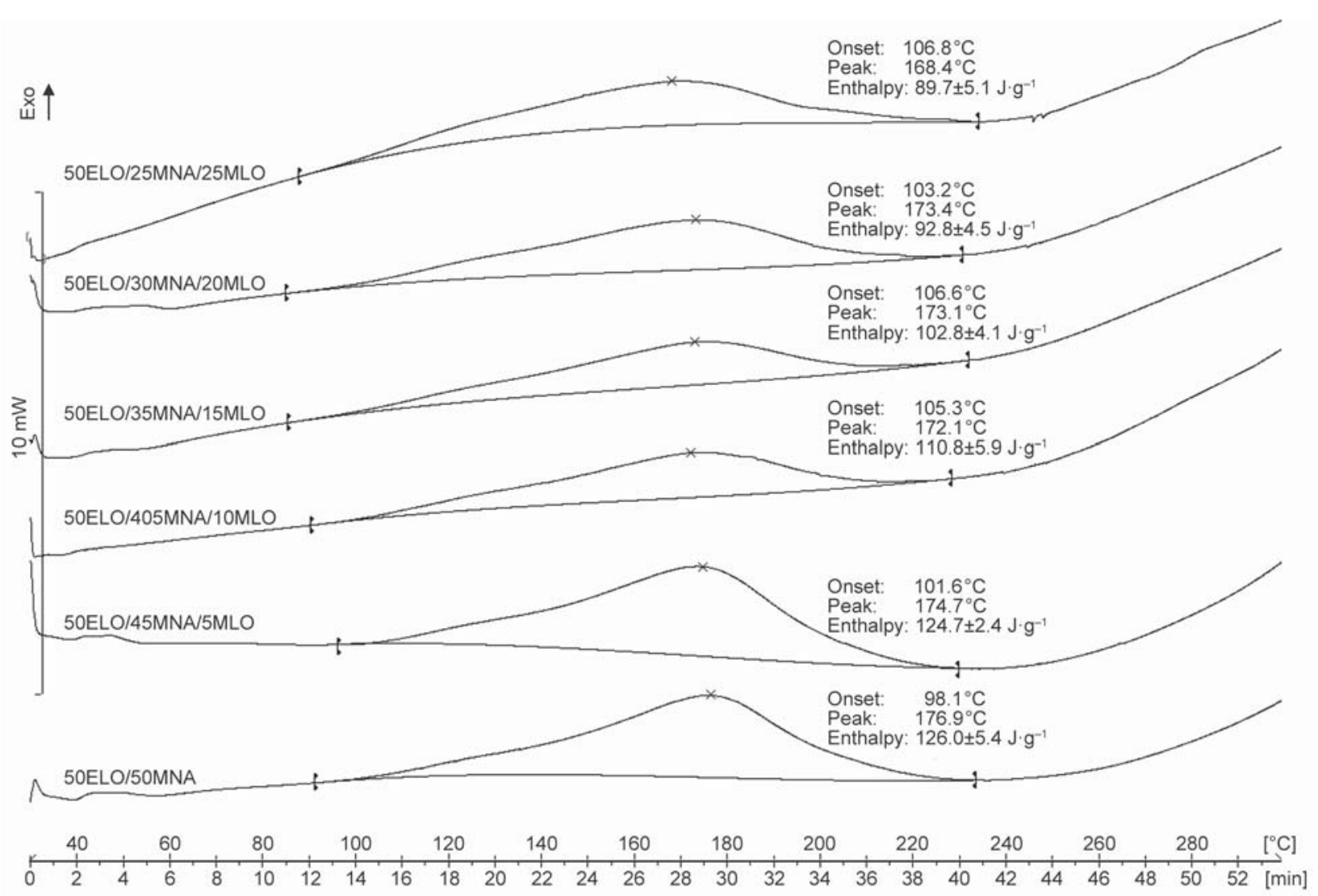

Figure 2. Plot comparison of the dynamic DSC thermograms of the curing process epoxidized linseed oil (ELO) crosslinked with a mixture of methyl nadic anhydride (MNA) and maleinized linseed oil (MLO).

time. The gel time can be defined as the mid-point between a fully liquid behaviour and a fully elastic solid behaviour. This implies a phase angle of $45^{\circ}$ and the values of both the storage modulus $\left(G^{\prime}\right)$ and the loss modulus $\left(G^{\prime \prime}\right)$ are equal (crossover point) [45]. To evaluate the curing conditions, the evolution of the storage modulus $\left(G^{\prime}\right)$, loss modulus $\left(G^{\prime \prime}\right)$ and the phase angle $(\delta)$ were collected on liquid resins cured at $110^{\circ} \mathrm{C}$ by $\mathrm{OR}$ as represented in Figure 3, and Table 2 shows a summary of the main parameters obtained. In particular, the onset $\left(\delta \approx 90^{\circ}\right)$, the endset $\left(\delta \approx 0^{\circ}\right)$ and the crossover point $\left(G^{\prime}=G^{\prime \prime}\right.$ or $\delta=$ $45^{\circ}$ ). It can be concluded that the reaction (crosslinking) rate is higher as the MLO content in the crosslinking mixture increases. These results are in total agreement with the previous DSC results which indicated
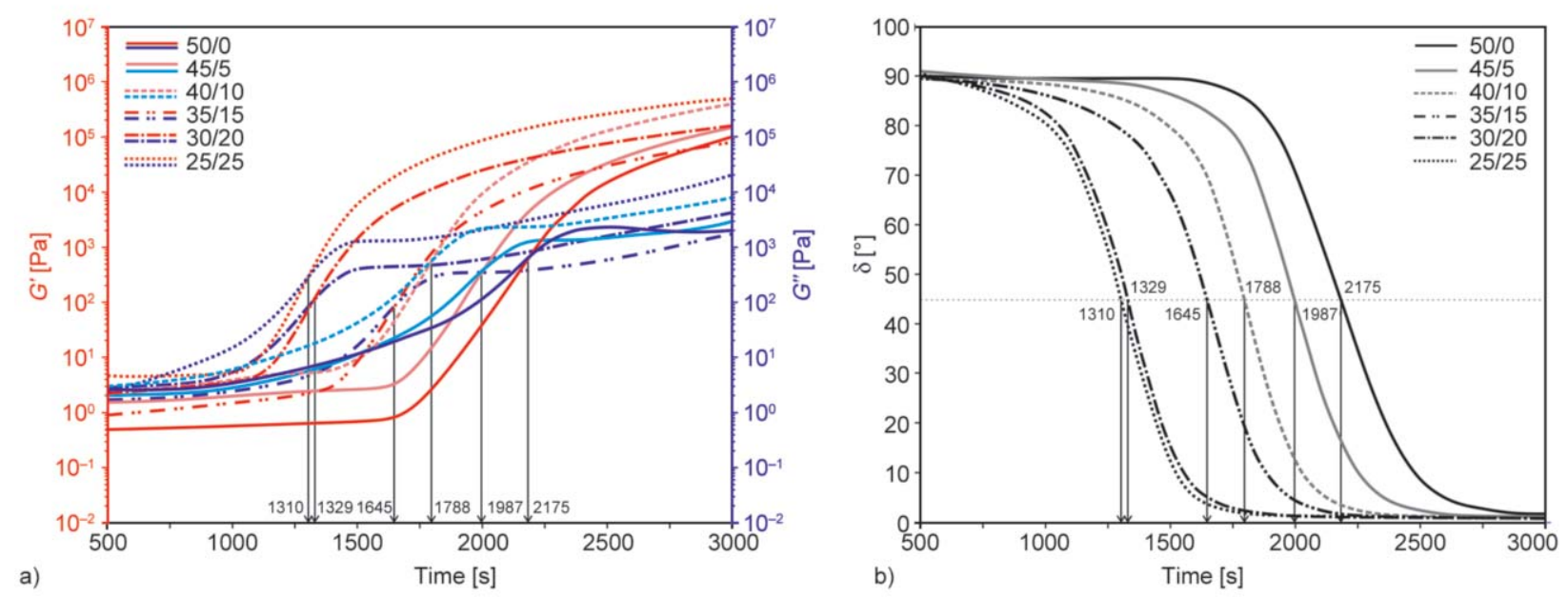

Figure 3. Variation of a) the storage modulus $\left(G^{\prime}\right)$ and loss modulus $\left(G^{\prime \prime}\right)$ and b) the phase angle $(\delta)$ of curing process of epoxidized linseed oil (ELO) crosslinked with a mixture of methyl nadic anhydride (MNA) and maleinized linseed oil (MLO), obtained by oscillatory rheometry (OR). 
Table 2. Main parameters of the curing process of epoxidized linseed oil (ELO) crosslinked with a mixture of methyl nadic anhydride (MNA) and maleinized linseed oil (MLO), obtained by oscillatory rheometry (OR).

\begin{tabular}{|c|c|c|c|c|}
\hline $\begin{array}{c}\text { MNA/MLO } \\
{[\mathbf{w t} / \mathbf{w t}]}\end{array}$ & $\begin{array}{c}\text { Crosslinking onset } \\
(\boldsymbol{\delta} \approx \mathbf{9 0}) \\
{[\mathbf{s}]}\end{array}$ & $\begin{array}{c}\boldsymbol{G}^{\prime}=\boldsymbol{G}^{\prime \prime} \\
{[\mathbf{P a}]}\end{array}$ & $\begin{array}{c}\text { Gel time } \\
\left(\boldsymbol{\delta}=\mathbf{4 5}^{\circ} ; \boldsymbol{G}^{\prime}=\boldsymbol{G}^{\prime \prime}\right) \\
{[\mathbf{s}]}\end{array}$ & $\begin{array}{c}\text { Crosslinking endset } \\
\left(\boldsymbol{\delta} \approx \mathbf{0}^{\circ}\right) \\
{[\mathbf{s}]}\end{array}$ \\
\hline $50 / 0$ & 1678 & 545 & 2175 & 2939 \\
\hline $45 / 5$ & 1658 & 307 & 1987 & 2605 \\
\hline $40 / 10$ & 1497 & 514 & 1788 & 2457 \\
\hline $35 / 15$ & 1439 & 111 & 1645 & 1849 \\
\hline $30 / 20$ & 1186 & 318 & 1329 & 1830 \\
\hline $25 / 25$ & 1149 & 1310 & 185 \\
\hline
\end{tabular}

a decrease in the peak temperature which is representative of the maximum reaction rate. So that, presence of MLO, accelerates the crosslinking process. For example, the ELO-system cured with the MNA/ MLO (50/0) mixture shows an onset, gel and endset times of 1678,2175 and $2939 \mathrm{~s}$ respectively. These characteristic times are remarkably reduced by increasing the MLO content, so, the ELO-system cured with a mixture MNA/MLO (25/25), shows reduced time values of 1145,1310 and $1830 \mathrm{~s}$ for the onset, gel and endset times, respectively. This represents a percentage decrease of about $30 \%$ with regard to the onset and a percentage decrease of almost $40 \%$ in the gel time and the endset time. This is an important feature from an industrial point of view as fully cured materials can be obtained with lower curing times. With these results, it was concluded that the use of isothermal conditions at $110^{\circ} \mathrm{C}$ for $2 \mathrm{~h}$ is enough to obtain fully cured materials with an average thickness of $4 \mathrm{~mm}$.

In addition to the cure cycle, a post-curing stage is useful to obtain the best mechanical properties in a

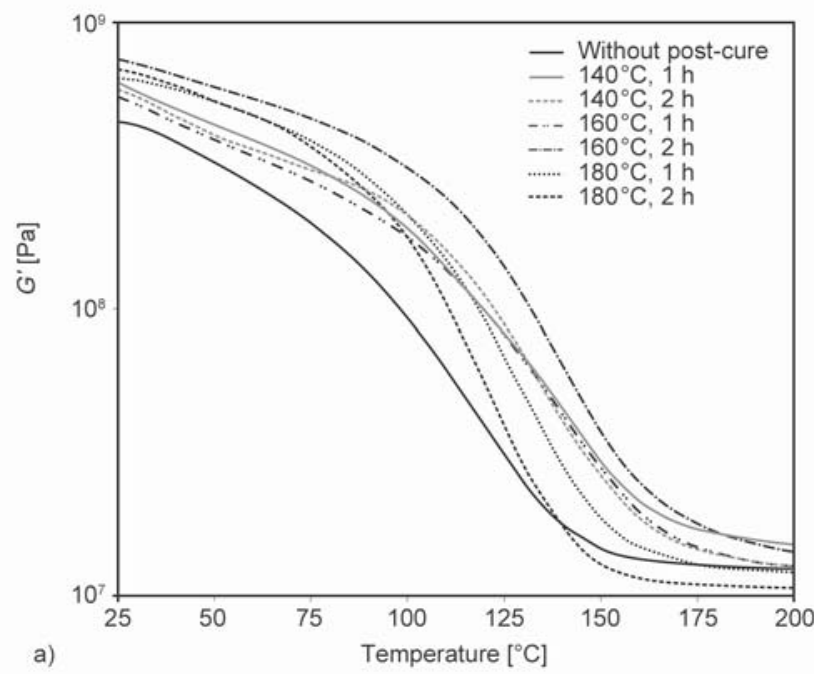

crosslinked polymer. The post-curing process can increase the crosslinking density thus leading to an increase in mechanical performance and in the glass transition temperatura $\left(T_{\mathrm{g}}\right)$ [47]. To evaluate the optimum post-curing conditions, the evolution of the storage modulus $\left(G^{\prime}\right)$ and the phase angle $(\delta)$ were collected on cured resin of the sample 0MLO (50 wt $\%$ ELO/50 wt $\%$ MNA) subjected to several post-curing conditions as represented in Figure 4 and Table 3 . It can be clearly seen that the glass transition temperature $\left(T_{\mathrm{g}}\right)$ increase after all the post-curing cycles. Thus, the $T_{\mathrm{g}}$ of the simply cured ELO resins is close to $126.4{ }^{\circ} \mathrm{C}$. Post-curing at $140^{\circ} \mathrm{C}$ for 1 additional hour leads to a remarkable increase in $T_{\mathrm{g}}$ up to $141.2^{\circ} \mathrm{C}$ and a slight increase up to $144.0^{\circ} \mathrm{C}$ is obtained after $2 \mathrm{~h}$ at $140^{\circ} \mathrm{C}$ post-curing. The most important changes are obtained after $1 \mathrm{~h}$ post-curing. The same situation can be observed for a post-curing cycle at $160^{\circ} \mathrm{C}$. The $\mathrm{Tg}$ is increased up to $147.7^{\circ} \mathrm{C}$ $(1 \mathrm{~h})$ and $147.4^{\circ} \mathrm{C}(2 \mathrm{~h})$. Nevertheless, although increased $T_{\mathrm{g}}$ values are obtained, these are lower than those observed at $160{ }^{\circ} \mathrm{C}$ thus indicating somewhat

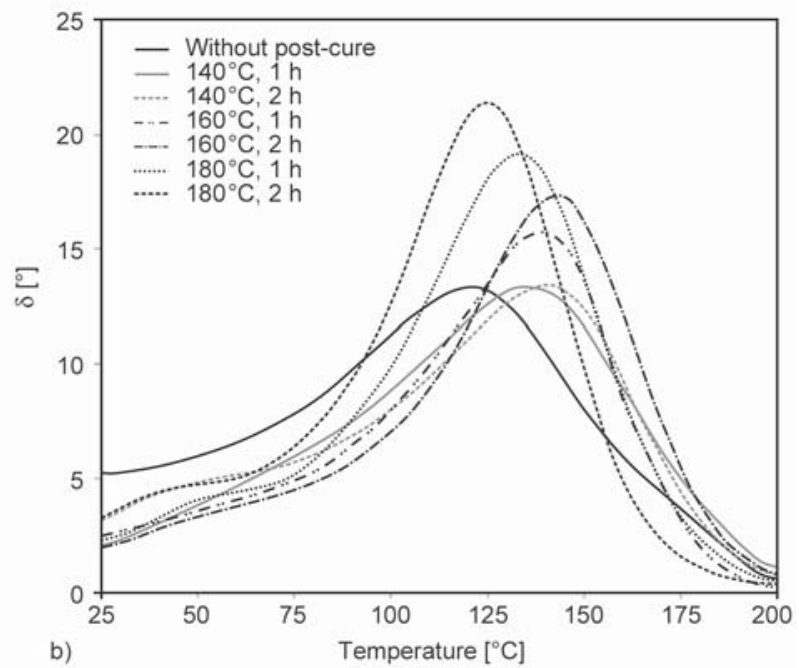

Figure 4. Variation of a) the storage modulus $\left(G^{\prime}\right)$ and b) the phase angle $(\delta)$ of crosslinked 0MLO (50 wt\% ELO/ $50 \mathrm{wt} \% \mathrm{MNA}$ ) with different post-curing conditions obtained by dynamic-mechanical thermal analysis (DMTA). 
Table 3. Variation of storage modulus at different temperatures and the phase angle $(\delta)$ of crosslinked 0MLO (50 wt $\%$ ELO/50 wt $\%$ MNA) with different postcuring conditions obtained by dynamic-mechanical thermal analysis (DMTA).

\begin{tabular}{|l|c|c|c|c|c|c|}
\hline \multirow{2}{*}{$\begin{array}{c}\text { Postcure } \\
\text { conditions }\end{array}$} & \multicolumn{5}{|c|}{$\begin{array}{c}\mathbf{G}^{\prime} \\
{[\mathbf{M P a}]}\end{array}$} & \multirow{2}{*}{$\begin{array}{c}\boldsymbol{T}_{\mathbf{g}} \\
{\left[{ }^{\circ} \mathbf{C}\right]}\end{array}$} \\
\cline { 2 - 7 } $\begin{array}{l}\text { Without } \\
\text { postcure }\end{array}$ & 495.6 & 238.4 & 119.6 & 15.6 & 13.7 & 126.4 \\
\hline $140^{\circ} \mathrm{C}, 1 \mathrm{~h}$ & 620.5 & 351.8 & 224.3 & 32.6 & 14.8 & 141.2 \\
\hline $140^{\circ} \mathrm{C}, 2 \mathrm{~h}$ & 615.2 & 309.3 & 203.0 & 33.2 & 12.2 & 144.0 \\
\hline $160^{\circ} \mathrm{C}, 1 \mathrm{~h}$ & 581.5 & 335.5 & 242.1 & 31.5 & 12.3 & 147.7 \\
\hline $160^{\circ} \mathrm{C}, 2 \mathrm{~h}$ & 809.3 & 504.3 & 356.0 & 46.3 & 14.2 & 147.4 \\
\hline $180^{\circ} \mathrm{C}, 1 \mathrm{~h}$ & 640.5 & 420.8 & 259.0 & 21.6 & 12.5 & 138.4 \\
\hline $180^{\circ} \mathrm{C}, 2 \mathrm{~h}$ & 648.2 & 309.3 & 203.0 & 33.2 & 12.2 & 144.0 \\
\hline
\end{tabular}

thermal degradation. With regard to the storage modulus $\left(G^{\prime}\right)$, all post-cured samples show increased $G^{\prime}$ values thus indicating the usefulness of the post-curing in enhancing mechanical performance. The highest $G^{\prime}$ values are obtained for a post-curing process at $160^{\circ} \mathrm{C}$ for $2 \mathrm{~h}$ which, finally, are the best post-curing conditions as both $T_{\mathrm{g}}$ and $G^{\prime}$ are remarkably increased in comparison to the other temperature-time conditions.

\subsection{Mechanical properties of ELO-based thermosetting resins crosslinked with MNA/MLO mixtures}

Table 4 shows a summary of the mechanical characterization (flexural properties and hardness) in terms of the MLO content in the crosslinking mixture. As it can be clearly seen, as the MLO content increases, both the flexural strength and modulus decrease thus indicating the flexibilization effect MLO can provide to these crosslinked resins. The ELO system cured with a MNA/MLO (50/0) mixture shows a flexural

Table 4. Summary of mechanical properties of epoxidized linseed oil (ELO) crosslinked with a mixture of methyl nadic anhydride (MNA) and maleinized linseed oil (MLO).

\begin{tabular}{|l|c|rr|r|}
\hline $\begin{array}{c}\text { MNA/MLO } \\
\text { [wt/wt] }\end{array}$ & $\begin{array}{c}\text { Flexural } \\
\text { strength } \\
\text { [MPa] }\end{array}$ & $\begin{array}{c}\text { Flexural } \\
\text { modulus } \\
\text { [MPa] }\end{array}$ & Shore D \\
\hline $50 / 0$ & $60.8(5.8)^{*}$ & $1772.0(132.0)$ & $82.2(2.5)$ \\
\hline $45 / 5$ & $54.9(5.4)$ & $1460.0(73.5)$ & $81.9(1.3)$ \\
\hline $40 / 10$ & $47.2(3.1)$ & $1027.0(46.5)$ & $78.2(1.9)$ \\
\hline $35 / 15$ & $31.9(4.8)$ & $718.2(45.2)$ & $76.1(1.5)$ \\
\hline $30 / 20$ & $23.8(0.5)$ & $485.8(33.0)$ & $71.4(1.8)$ \\
\hline $25 / 25$ & $14.5(0.6)$ & $272.3(20.9)$ & $64.1(1.5)$ \\
\hline
\end{tabular}

${ }^{*}$ The numbers in parentheses stand for the standard deviation. strength of $60.8 \mathrm{MPa}$ and a flexural modulus of about $1.7 \mathrm{GPa}$. As it can be seen when $5 \mathrm{wt} \% \mathrm{MNA}$ is replaced by MLO, MNA/MLO (45/5), the tensile strength decreases down to $54.9 \mathrm{MPa}$ while the flexural modulus goes down to $1.46 \mathrm{GPa}$. The decrease in both flexural strength and modulus follows a linear tendency, as it can be seen in Figure 5. The ELO system crosslinked with a MNA/MLO (25/25) mixture shows remarkably reduced flexural properties: the flexural strength is $14.5 \mathrm{MPa}$ and the flexural modulus is close to $0.27 \mathrm{GPa}$. This decrease in mechanical resistant properties is directly related to the chemical structure of the crosslinkers. On one hand, MNA is a cyclic anhydride which gives high rigidity. On the other hand, the triglyceride structure, shows linear chains corresponding to the different functionalized fatty acids and these linear chains can positively contribute to increase flexibility, thus reducing the stiffness. The effect of MNA and MLO on flexibility can be seen in Figure 6 .

The Shore D hardness follows the same tendency as flexural resistant properties. The system cured with MNA/MLO (50/0) mixture, shows the highest Shore D value of about 82.2 which is reduced down to values around 64.1 by replacing $25 \mathrm{wt} \%$ MNA by MLO, MNA/MLO (25/25) mixture. All these results are in total agreement with the previous DSC results since

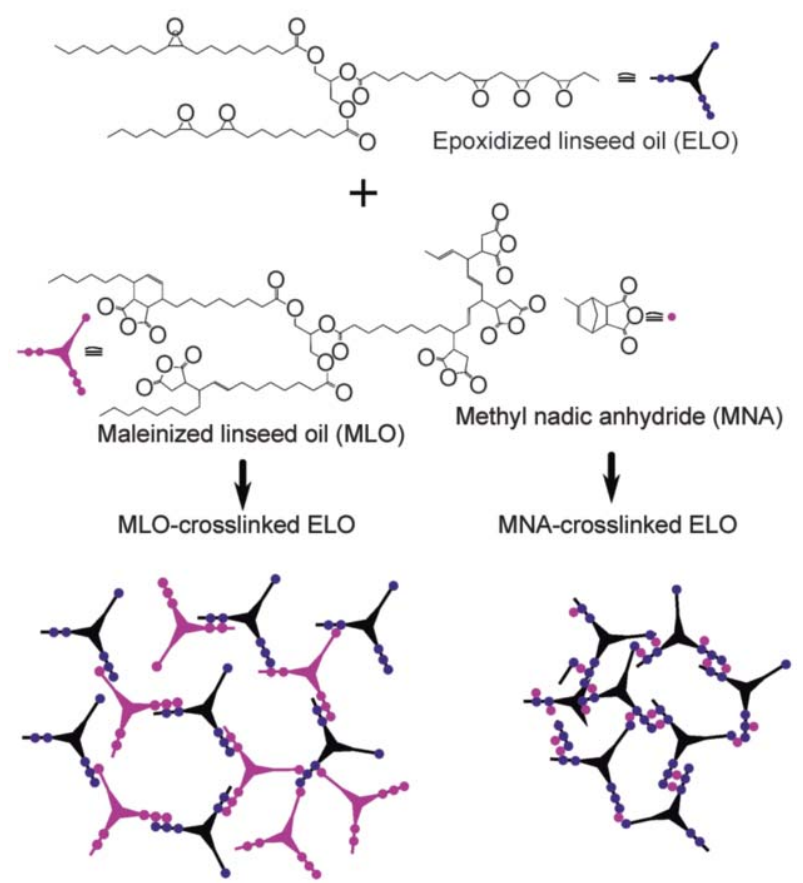

Figure 5. Schematic plot of the effect of methyl nadic anhydride (MNA) and maleinized linseed oil (MLO) on crosslinked epoxidized linseed oil (ELO) structures. 


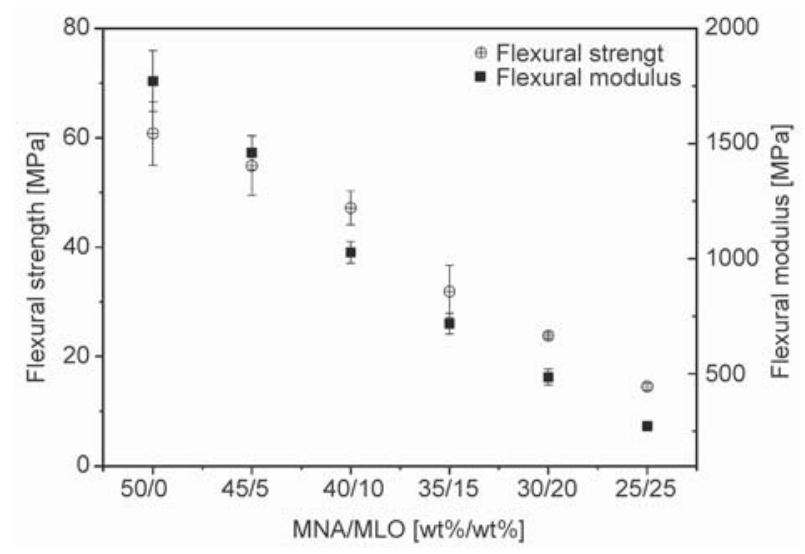

Figure 6. Flexural properties of epoxidized linseed oil (ELO) crosslinked with a mixture of methyl nadic anhydride (MNA) and maleinized linseed oil (MLO).

the peak enthalpy decreased as the MLO content increased, thus indicating less intensity of the crosslinking reactions with the subsequent effect on mechanical properties as corroborated by flexural tests and harness measurements. As one can see, the use of MLO as co-hardener leads to a remarkable change on overall properties. By selecting a proper MNA/ MLO ratio, it is possible to obtain a wide range of mechanical properties from high stiffness materials (high MNA content) to flexible thermosetting ELObased materials for MNA/MLO ratios of 50:50. It seems that the 40:10 for MNA/MLO ratio gives good balanced properties in terms of resistance and deformation but if we are looking for flexible thermosetting materials, higher amounts of MLO co-hardener can be employed.
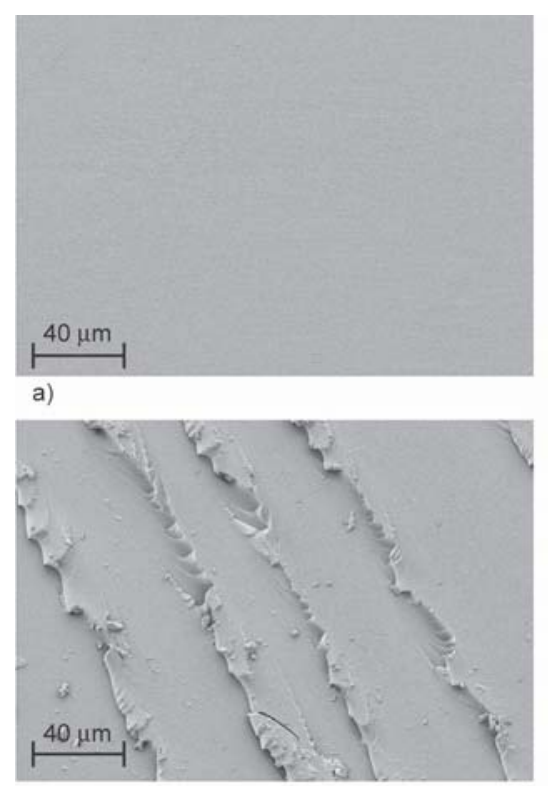

d)

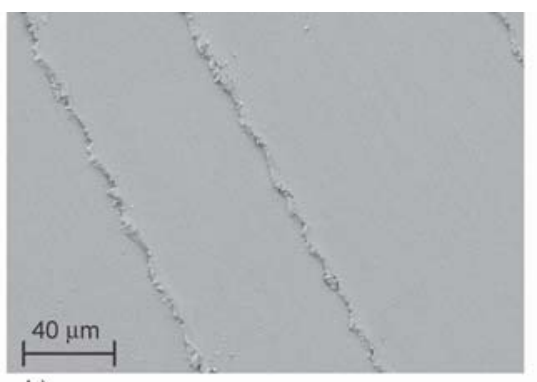

b)

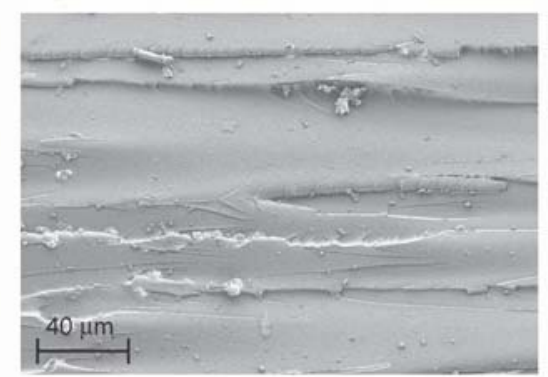

e)
To support the results obtained by flexural tests, cryofractured surfaces were observed by field emission scanning electron microscopy (FESEM) (Figure 7). The ELO system crosslinked with a MNA/MLO $(50 / 0)$ mixture shows a smooth and homogeneous surface, typical of brittle polymers (Figure 7a). The effects of MLO on fractured surfaces is detectable even for low MLO content mixtures, MNA/MLO $(45 / 5)$ as it can be seen in Figure $7 \mathrm{~b}$ in which presence of several crack fronts can be observed which are directly related to increased flexibility. As the MLO ratio in MNA/MLO crosslinking mixtures increases (Figure 7c-7f), the number of crack fronts increase in both size and number, thus indicating increased ductility. These findings are in agreement with the flexural results that indicated the role of MLO in increasing ductility.

\subsection{Thermo-mechanical properties of ELO-based thermosetting resins crosslinked with MNA/MLO mixtures}

Once the post-curing cycle was defined, all cured and post-cured ELO materials crosslinked with MNA/ MLO mixtures were characterized by DMTA and the main parameters (storage modulus $-G^{\prime}$ and phase angle $-\delta$ ) were evaluated. The main results can be observed in Figure 8. As can be seen, the glass transition temperature $\left(T_{\mathrm{g}}\right)$ decreases as the MLO content in MNA/MLO mixtures increases. The $T_{\mathrm{g}}$ of the ELOsystem crosslinked with a MNA/MLO (50/0) mixture reaches high values of $150.5^{\circ} \mathrm{C}$. The flexibilization

Figure 7. Field emission scanning electron microscopy (FESEM) images Corresponding to fractured samples of crosslinked ELO with a mixture of MNA/MLO [wt/wt], a) (50/0), b) $(45 / 5)$, c) $(40 / 10)$, d) $(35 / 15)$, e) $(30 / 20)$ and f) $(25 / 25)$. 

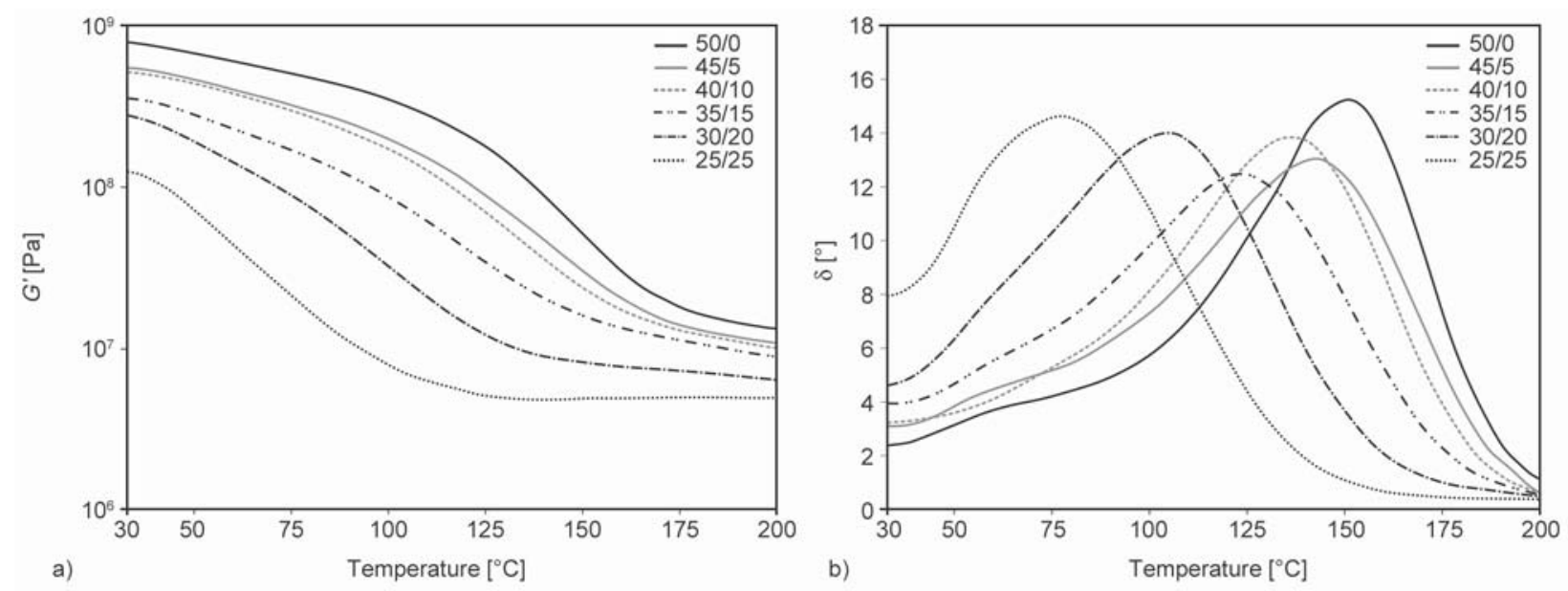

Figure 8. Variation of a) the storage modulus $\left(G^{\prime}\right)$ and b) the phase angle $(\delta)$ of ELO-based resins crosslinked with a mixture of methyl nadic anhydride (MNA) and maleinized linseed oil (MLO), obtained by dynamic-mechanical thermal analysis (DMTA).

effect of MLO can be seen in ELO-system crosslinked with a MNA/MLO (45/5) mixture as the $T_{\mathrm{g}}$ goes down to values of $141.0^{\circ} \mathrm{C}$. This decreasing tendency is maintained and the crosslinked ELO-system with a MNA/MLO (25/25) mixture shows remarkably low $T_{\mathrm{g}}$ values of $75.8^{\circ} \mathrm{C}$, as seen in Figure $8 \mathrm{~b}$. Furthermore, the effects of MLO are also detectable by following the evolution of $G^{\prime}$. The highest $G^{\prime}$ values are obtained for the ELO-system crosslinked with MNA/MLO (50/0) due to the high rigidity of the MNA molecule compared to MLO structure. As the MLO content in MNA/MLO mixtures increases, $G^{\prime}$ also moves to lower values as seen in Figure 8a. MLO contributes to more flexible materials thus giving the possibility of tailoring the desired mechanical properties by selecting the appropriate MNA/MLO crosslinking mixture.

The thermomechanical properties of the ELO-system crosslinked with different MNA/MLO mixtures are summarized in Table 5. With regard to thermomechanical analysis (TMA), the $T_{\mathrm{g}}$ was obtained through the change in the slope of the linear expansion versus

Table 5. Thermomechanical properties of ELO-based resins crosslinked with a mixture of methyl nadic anhydride (MNA) and maleinized linseed oil (MLO).

\begin{tabular}{|l|c|c|c|}
\hline $\begin{array}{c}\text { MNA/MLO } \\
{[\mathbf{w t} / \mathbf{w t}]}\end{array}$ & $\begin{array}{c}\text { TMA }\left(\boldsymbol{T}_{\mathrm{g}}\right) \\
{\left[{ }^{\circ} \mathbf{C}\right]}\end{array}$ & $\begin{array}{c}\text { VST } \\
{\left[{ }^{\circ} \mathbf{C}\right]}\end{array}$ & $\begin{array}{c}\text { HDT } \\
{\left[{ }^{\circ} \mathbf{C}\right]}\end{array}$ \\
\hline $50 / 0$ & 138.8 & 133.4 & 78.2 \\
\hline $45 / 5$ & 131.1 & 123.8 & 69.8 \\
\hline $40 / 10$ & 125.2 & 113.0 & 64.8 \\
\hline $35 / 15$ & 120.7 & 96.0 & 57.4 \\
\hline $30 / 20$ & 99.9 & 63.4 & 50.6 \\
\hline $25 / 25$ & 68.7 & 42.4 & 40.6 \\
\hline
\end{tabular}

temperature. These $T_{\mathrm{g}}$ values follow the same tendency as those obtained by DMTA analysis. With regard to the heat deflection tendency (HDT) and Vicat softening temperature (VST) it is worthy to note the same decreasing tendency as the MLO content in MNA/MLO mixtures increases. These results are in total accordance with previous flexural properties as well as dynamic-mechanical thermal analysis, showing the potential of MLO to give flexibility to crosslinked ELO resins. In particular, by replacing up to $25 \mathrm{wt} \%$ MNA by MLO, it is possible to obtain a HDT range from $78.2^{\circ} \mathrm{C}$ (using only MNA as crosslinker) to $40.6^{\circ} \mathrm{C}$ using a MNA/MLO $(25 / 25)$ mixture. With regard to VST, by selecting the appropriate MLO content, it is possible to obtain flexible (low thermal stability) materials with a VST of $42.4^{\circ} \mathrm{C}$ using a MNA/ MLO $(25 / 25)$ and also high thermally stable materials with VST values of $133.4^{\circ} \mathrm{C}$ using a MNA/MLO $(50 / 0)$ mixture as crosslinking agent.

If we compare the results obtained in this work with other epoxidized vegetable oil cured with different crosslinking agents made in previous works (Table 6) $[15,22]$, it showed that some epoxy resins developed in this work present better mechanical and thermomechanical properties than epoxy resins cured with maleic anhydride and a mix of maleic anhydride (MA) and phthalic anhydride (PA). The most important difference is found in the reduction of the crosslinking agent of petro origin maintaining a good balance in the mechanical and thermomechanical properties. With the obtained result the resin 50ELO: 40MNA:10MLO might be a good candidate to use as a matrix in green composite materials. 
Table 6. A comparison of mechanical and thermomechanical properties of EVO based epoxy resins crosslinked with different agents.

\begin{tabular}{|c|c|c|c|c|c|c|c|c|}
\hline \multicolumn{2}{|c|}{ Epoxy resin } & \multirow{2}{*}{$\begin{array}{c}\text { Flexural modulus } \\
{[\mathrm{MPa}]}\end{array}$} & \multirow{2}{*}{$\begin{array}{c}\text { Flexural strength } \\
{[\mathrm{MPa}]}\end{array}$} & \multirow{2}{*}{ Shore D } & \multirow{2}{*}{$\begin{array}{l}\text { VST } \\
{\left[{ }^{\circ} \mathrm{C}\right]}\end{array}$} & \multirow{2}{*}{$\begin{array}{l}\text { HDT } \\
{\left[{ }^{\circ} \mathrm{C}\right]}\end{array}$} & \multirow{2}{*}{$\begin{array}{c}\text { TMA }\left(T_{\mathrm{g}}\right) \\
{\left[{ }^{\circ} \mathrm{C}\right]}\end{array}$} & \multirow{2}{*}{ Ref. } \\
\hline EVO & Crosslinking & & & & & & & \\
\hline ELO & MNA & 1772.0 & 60.8 & 82.2 & 133.4 & 78.2 & 138.8 & t.w. \\
\hline ELO & 40MNA/10MLO & 1027.0 & 47.2 & 78.2 & 113.0 & 64.8 & 125.2 & t.w. ${ }^{*}$ \\
\hline ELO & 60MNA/40MLO & 485.8 & 23.8 & 71.4 & 99.9 & 63.4 & 50.6 & t.w. ${ }^{*}$ \\
\hline ESBO & MNA (1:0.9) & 334.1 & 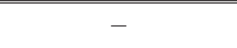 & 69.0 & 45.9 & 28.0 & 42.6 & {$[22]$} \\
\hline ESBO & MNA (1:1) & 432.0 & - & 70.0 & 46.0 & 31.2 & 36.3 & {$[22]$} \\
\hline ESBO & MNA (1:1.1) & 420.9 & - & 66.3 & 45.1 & 29.8 & 34.7 & {$[22]$} \\
\hline ELO & PA/MA & 622.8 & 35.8 & 66.5 & 88.8 & 65.0 & 37.2 & {$[15]$} \\
\hline 80ELO/20ESBO & PA/MA & 676.4 & 33.4 & 63.3 & 73.2 & 53.8 & 33.2 & {$[15]$} \\
\hline ESBO & $\mathrm{PA} / \mathrm{MA}$ & 11.1 & 1.3 & 21.9 & - & - & 27.0 & {$[15]$} \\
\hline
\end{tabular}

t.w.: it means this work

\section{Conclusions}

The herein obtained results suggest the usefulness of maleinized linseed oil (MLO) as renewable co-crosslinker for epoxidized linseed oil (ELO) together with a petroleum-based crosslinker such as methyl nadic anhydride (MNA), thus leading to high renewable content crosslinked epoxies. The calorimetric study revealed that MLO accelerates the crosslinking reaction as the peak temperature is moved towards lower temperatures while the peak enthalpy decreases with increasing MLO content. During a dynamic curing cycle, the crosslinking process starts at about $80-100{ }^{\circ} \mathrm{C}$ and finishes at $225-235^{\circ} \mathrm{C}$. Isothermal cure at $110^{\circ} \mathrm{C} / 2 \mathrm{~h}$ gives the best balanced properties in terms of mechanical and thermal properties. As the MLO content increases, the gel time decreases thus showing a faster crosslinking process. Post-curing cycle is necessary to reach the best mechanical and thermal performance. The obtained results suggest that a post-curing cycle at $160^{\circ} \mathrm{C}$ and 2 addition hours gives the best mechanical properties together with the highest $T_{\mathrm{g}}$ values. MLO molecules are more flexible than MNA and this fact is responsible for a decrease in stiffness in ELO-cured resins as the MLO content increases thus giving the possibility of tailoring the desired mechanical and thermal properties on ELO-based resins by selecting the appropriate amount of MLO. In addition, as the MLO content increases, the renewable content also increases which is an important feature from an environmental point of view.

\section{Acknowledgements}

This work has been supported by the Spanish Ministry of Economy and Competitiveness, PROMADEPCOL (MAT2017-84909-C2-2-R). MDS is recipient of a APOSTD2018 contract (APOSTD/2018/209) from Conselleria d'Educació, Investigació, Cultura y Esport de la Generalitat Valenciana.

\section{References}

[1] Vert M., Schwarch G., Coudane J.: Present and future of PLA polymers. Journal of Macromolecular Science Part A: Pure and Applied Chemistry, 32, 787-796 (1995).

https://doi.org/10.1080/10601329508010289

[2] Woodruff M. A., Hutmacher D. W.: The return of a forgotten polymer - Polycaprolactone in the 21 st century. Progress in Polymer Science, 35, 1217-1256 (2010). https://doi.org/10.1016/j.progpolymsci.2010.04.002

[3] Kim H-S., Yang H-S., Kim H-J.: Biodegradability and mechanical properties of agro-flour-filled polybutylene succinate biocomposites. Journal of Applied Polymer Science, 97, 1513-1521 (2005). https://doi.org/10.1002/app.21905

[4] Xu J., Guo B-H.: Poly(butylene succinate) and its copolymers: Research, development and industrialization. Biotechnology Journal, 5, 1149-1163 (2010). https://doi.org/10.1002/biot.201000136

[5] Carbonell-Verdu A., Ferri J. M., Dominici F., Boronat T., Sanchez-Nacher L., Balart R., Torre L.: Manufacturing and compatibilization of PLA/PBAT binary blends by cottonseed oil-based derivatives. Express Polymer Letters, 12, 808-823 (2018).

https://doi.org/10.3144/expresspolymlett.2018.69

[6] Hazer B., Steinbüchel A.: Increased diversification of polyhydroxyalkanoates by modification reactions for industrial and medical applications. Applied Microbiology and Biotechnology, 74, 1-12 (2007).

https://doi.org/10.1007/s00253-006-0732-8 
[7] Hazer D. B., Kılıçay E., Hazer B.: Poly(3-hydroxyalkanoate)s: Diversification and biomedical applications: A state of the art review. Materials Science and Engineering: C, 32, 637-647 (2012).

https://doi.org/10.1016/j.msec.2012.01.021

[8] Fourati Y., Hassen R. B., Bayramoğlu G., Boufi S.: A one step route synthesis of polyurethane newtwork from epoxidized rapeseed oil. Progress in Organic Coatings, 105, 48-55 (2017).

https://doi.org/10.1016/j.porgcoat.2016.12.021

[9] Akram D., Hakami O., Sharmin E., Ahmad S.: Castor and linseed oil polyurethane/TEOS hybrids as protective coatings: A synergistic approach utilising plant oil polyols, a sustainable resource. Progress in Organic Coatings, 108, 1-14 (2017).

https://doi.org/10.1016/j.porgcoat.2017.03.012

[10] Karadeniz K., Çalıkoğlu Y., Sen M. Y.: A novel polyurethanes from epoxidized soybean oil synthesized by ring opening with bifunctional compounds. Polymer Bulletin, 74, 2819-2839 (2017).

https://doi.org/10.1007/s00289-016-1867-0

[11] Patil C. K., Rajput S. D., Marathe R. J., Kulkarni R. D., Phadnis H., Sohn D., Mahulikar P. P., Gite V. V.: Synthesis of bio-based polyurethane coatings from vegetable oil and dicarboxylic acids. Progress in Organic Coatings, 106, 87-95 (2017).

https://doi.org/10.1016/j.porgcoat.2016.11.024

[12] Flint S., Markle T., Thompson S., Wallace E.: Bisphenol A exposure, effects, and policy: A wildlife perspective. Journal of Environmental Management, 104, 19 34 (2012).

https://doi.org/10.1016/j.jenvman.2012.03.021

[13] Kasetaite S., Ostrauskaite J., Grazuleviciene V., Svediene J., Bridziuviene D.: Camelina oil- and linseed oilbased polymers with bisphosphonate crosslinks. Journal of Applied Polymer Science, 131, 40683/1-40683/8 (2014).

https://doi.org/10.1002/app.40683

[14] Mazzon E., Habas-Ulloa A., Habas J-P.: Lightweight rigid foams from highly reactive epoxy resins derived from vegetable oil for automotive applications. European Polymer Journal, 68, 546-557 (2015).

https://doi.org/10.1016/j.eurpolymj.2015.03.064

[15] Samper M. D., Fombuena V., Boronat T., GarciaSanoguera D., Balart R.: Thermal and mechanical characterization of epoxy resins (ELO and ESO) cured with anhydrides. Journal of the American Oil Chemists' Society, 89, 1521-1528 (2012).

https://doi.org/10.1007/s11746-012-2041-y

[16] Tsujimoto T., Takeshita K., Uyama H.: Bio-based epoxy resins from epoxidized plant oils and their shape memory behaviors. Journal of the American Oil Chemists' Society, 93, 1663-1669 (2016).

https://doi.org/10.1007/s11746-016-2907-5
[17] Jebrane M., Cai S., Sandström C., Terziev N.: The reactivity of linseed and soybean oil with different epoxidation degree towards vinyl acetate and impact of the resulting copolymer on the wood durability. Express Polymer Letters, 11, 383-395 (2017).

https://doi.org/10.3144/expresspolymlett.2017.37

[18] Chen Y., Xi Z., Zhao L.: Curing kinetics of bio-based epoxy resin based on epoxidized soybean oil and green curing agent. AIChE Journal, 63, 147-153 (2017). https://doi.org/10.1002/aic.15486

[19] Li Y. T., Yang L. T., Zhang H., Tang Z. J.: Synthesis and properties of a novel bio-based polymer from modified soybean oil. IOP Conference Series: Materials Science and Engineering, 170, 012010/1-012010/7 (2017). https://doi.org/10.1088/1757-899X/170/1/012010

[20] Liu K., Madbouly S. A., Kessler M. R.: Biorenewable thermosetting copolymer based on soybean oil and eugenol. European Polymer Journal, 69, 16-28 (2015). https://doi.org/10.1016/j.eurpolymj.2015.05.021

[21] Roudsari G. M., Mohanty A. K., Misra M.: Study of the curing kinetics of epoxy resins with biobased hardener and epoxidized soybean oil. ACS Sustainable Chemistry and Engineering, 2, 2111-2116 (2014).

https://doi.org/10.1021/sc500176z

[22] Espana J., Sánchez-Nacher L., Boronat T., Fombuena V., Balart R.: Properties of biobased epoxy resins from epoxidized soybean oil (ESBO) cured with maleic anhydride (MA). Journal of the American Oil Chemists' Society, 89, 2067-2075 (2012). https://doi.org/10.1007/s11746-012-2102-2

[23] Fombuena V., Sánchez-Nácher L., Samper M., Juárez D., Balart R.: Study of the properties of thermoset materials derived from epoxidized soybean oil and protein fillers. Journal of the American Oil Chemists' Society, 90, 449-457 (2013).

https://doi.org/10.1007/s11746-012-2171-2

[24] Uysal N., Acik G., Tasdelen M. A.: Soybean oil based thermoset networks via photoinduced CuAAC click chemistry. Polymer International, 66, 999-1004 (2017). https://doi.org/10.1002/pi.5346

[25] Negrell C., Cornille A., de Andrade Nascimento P., Robin J-J., Caillol S.: New bio-based epoxy materials and foams from microalgal oil. European Journal of Lipid Science and Technology, 119, 1600214/11600214/13 (2017).

https://doi.org/10.1002/ejlt.201600214

[26] Sammaiah A., Padmaja K. V., Suresh K. I., Prasad R. B. N.: Effect of epoxidized jatropha oil on the cure, thermal, morphological and viscoelastic properties of epoxy resins. Journal of Renewable Materials, 4, 113-122 (2016). https://doi.org/10.7569/jrm.2015.634118

[27] Kadam A., Pawar M., Yemul O., Thamke V., Kodam K.: Biodegradable biobased epoxy resin from karanja oil. Polymer, 72, 82-92 (2015). https://doi.org/10.1016/j.polymer.2015.07.002 
[28] Meiorin C., Aranguren M. I., Mosiewicki M. A.: Polymeric networks based on tung oil: Reaction and modification with green oil monomers. European Polymer Journal, 67, 551-560 (2015).

https://doi.org/10.1016/j.eurpolymj.2015.01.005

[29] Carbonell-Verdu A., Bernardi L., Garcia-Garcia D., Sanchez-Nacher L., Balart R.: Development of environmentally friendly composite matrices from epoxidized cottonseed oil. European Polymer Journal, 63, 1 10 (2015).

https://doi.org/10.1016/j.eurpolymj.2014.11.043

[30] Mustata F., Tudorachi N., Bicu I.: Curing kinetics, thermal and morphological characterization of the biobased thermosets from epoxy resin/epoxidized hemp oil. Journal of Analytical and Applied Pyrolysis, 122, 191-201 (2016). https://doi.org/10.1016/j.jaap.2016.09.024

[31] Fache M., Boutevin B., Caillol S.: Epoxy thermosets from model mixtures of the lignin-to-vanillin process. Green Chemistry, 18, 712-725 (2016).

https://doi.org/10.1039/c5gc01070e

[32] Nikafshar S., Zabihi O., Hamidi S., Moradi Y., Barzegar S., Ahmadi M., Naebe M.: A renewable bio-based epoxy resin with improved mechanical performance that can compete with DGEBA. RSC Advances, 7, 8694-8701 (2017). https://doi.org/10.1039/c6ra27283e

[33] Shibata M., Ohkita T.: Fully biobased epoxy resin systems composed of a vanillin-derived epoxy resin and renewable phenolic hardeners. European Polymer Journal, 92, 165-173 (2017).

https://doi.org/10.1016/j.eurpolymj.2017.05.007

[34] Ménard R., Caillol S., Allais F.: Ferulic acid-based renewable esters and amides-containing epoxy thermosets from wheat bran and beetroot pulp: Chemo-enzymatic synthesis and thermo-mechanical properties characterization. Industrial Crops and Products, 95, 83 95 (2017).

https://doi.org/10.1016/j.indcrop.2016.10.016

[35] Brocas A-L., Llevot A., Mantzaridis C., Cendejas G., Auvergne R., Caillol S., Carlotti S., Cramail H.: Epoxidized rosin acids as co-precursors for epoxy resins. Designed Monomers and Polymers, 17, 301-310 (2014). https://doi.org/10.1080/15685551.2013.840504

[36] Baroncini E. A., Yadav S. K., Palmese G. R., Stanzione J. F.: Recent advances in bio-based epoxy resins and bio-based epoxy curing agents. Journal of Applied Polymer Science, 133, 44103/1-44103/19 (2016). https://doi.org/10.1002/app.44103

[37] Yang X., Wang C., Li S., Huang K., Li M., Mao W., Cao S., Xia J.: Study on the synthesis of bio-based epoxy curing agent derived from myrcene and castor oil and the properties of the cured products. RSC Advances, 7, 238-247 (2017).

https://doi.org/10.1039/c6ra24818g
[38] Darroman E., Bonnot L., Auvergne R., Boutevin B., Caillol S.: New aromatic amine based on cardanol giving new biobased epoxy networks with cardanol. European Journal of Lipid Science and Technology, 117, 178-189 (2015).

https://doi.org/10.1002/ejlt.201400248

[39] Stemmelen M., Pessel F., Lapinte V., Caillol S., Habas J-P., Robin J-J.: A fully biobased epoxy resin from vegetable oils: From the synthesis of the precursors by thiol-ene reaction to the study of the final material. Journal of Polymer Science Part A: Polymer Chemistry, 49, 2434-2444 (2011).

https://doi.org/10.1002/pola.24674

[40] Mak K., Fam A., MacDougall C.: Flexural behavior of sandwich panels with bio-FRP skins made of flax fibers and epoxidized pine-oil resin. Journal of Composites for Construction, 19, 1-13 (2015).

https://doi.org/10.1061/(asce)cc.1943-5614.0000560

[41] Taylor C., Amiri A., Paramarta A., Ulven C., Webster D.: Development and weatherability of bio-based composites of structural quality using flax fiber and epoxidized sucrose soyate. Materials and Design, 113, 1726 (2017).

https://doi.org/10.1016/j.matdes.2016.10.002

[42] Sahoo S. K., Mohanty S., Nayak S. K.: Mechanical, thermal, and interfacial characterization of randomly oriented short sisal fibers reinforced epoxy composite modified with epoxidized soybean oil. Journal of Natural Fibers, 14, 357-367 (2017).

https://doi.org/10.1080/15440478.2016.1212757

[43] Di Landro L., Janszen G.: Composites with hemp reinforcement and bio-based epoxy matrix. Composites Part B: Engineering, 67, 220-226 (2014).

https://doi.org/10.1016/j.compositesb.2014.07.021

[44] Oliveira A., Becker C., Amico S. C.: The effect of degassing agents on the characteristics of epoxy/glass fiber composites. Polimeros-Ciencia E Tecnologia, 24, 117-122 (2014). https://doi.org/10.4322/polimeros.2014.059

[45] Samper M. D., Petrucci R., Sanchez-Nacher L., Balart R., Kenny J. M.: Properties of composite laminates based on basalt fibers with epoxidized vegetable oils. Materials and Design, 72, 9-15 (2015). https://doi.org/10.1016/j.matdes.2015.02.002

[46] Samper M. D., Petrucci R., Sánchez-Nacher L., Balart R., Kenny J. M.: New environmentally friendly composite laminates with epoxidized linseed oil (ELO) and slate fiber fabrics. Composites Part B: Engineering, 71, 203-209 (2015).

https://doi.org/10.1016/j.compositesb.2014.11.034

[47] Abenojar J., Velasco F., Martínez M. A.: Influencia del post-curado en las propiedades mecánicas de una resina epoxi reforzada con sic: Estudio estadístico (in Spanish). Revista Iberoamericana de Polímeros, 10, 166179 (2009). 